\title{
Meninas.comp: Um Relato da Experiência de Integração entre o Ensino Médio e a Universidade de Brasília
}

\author{
Maristela Holanda ${ }^{1}$, Aleteia Patrícia F. de Araújo ${ }^{1}$, Maria Emília T. Walter ${ }^{1}$, \\ Carlos Alberto Jesus de Oliveira ${ }^{2}$ \\ ${ }^{1}$ Departamento de Ciência da Computação - Universidade de Brasília (UnB) \\ Campus Darcy Ribeiro - CEP 70910-900 - Brasília - DF - Brasil \\ ${ }^{2}$ Centro de Ensino Médio Paulo Freire \\ Asa Norte SGAN 610 - CEP 70860-100 - Brasília - DF - Brasil
}

\begin{abstract}
This article reports some integration actions among girls at high school and the University of Brasilia (UnB), in computer science. These actions were developed as part of the project Meninas.comp, coordinated by female Professors of the Department of Computer Science at UnB. The project Meninas.comp has the main objective of publicizing the computer science area to the girls of the public high schools of Distrito Federal, at Brazil.
\end{abstract}

Resumo. Este artigo relata atividades de integração entre meninas de escola de Ensino Médio e a Universidade de Brasília (UnB), em computação. As atividades foram desenvolvidas como parte das ações do projeto Meninas.comp, coordenadas por docentes mulheres do Departamento de Ciência da Computação da UnB. O projeto Meninas.comp tem como principal objetivo a divulgação da área de computação para meninas do ensino médio de escolas públicas do Distrito Federal, no Brasil.

\section{Introdução}

Nos últimos anos, vem sendo realizadas discussões sobre as razões da incipiente participação feminina na área de Computação, além de estratégias para atrair as meninas para essa área [Cohoon, 2002], [Gurer, 2002], [Maia, 2016], [Khan, 2016]. Computação não parece ser a primeira escolha de formação universitária dessas jovens, que no Ensino Médio devem decidir sobre as suas possibilidades de atuação profissional. Esse fenômeno também ocorre no Distrito Federal, no Brasil. Nesse contexto, no ano de 2010, iniciou-se na Universidade de Brasília (UnB) o projeto "Meninas.comp", com o objetivo de apresentar a área de Computação para alunas do ensino médio de escolas públicas do Distrito Federal, de modo que elas pensassem nos cursos de Computação como possibilidades entre as suas escolhas profissionais.

O projeto "Meninas comp" propõe diversas ações, que promovem a discussão das atividades profissionais das mulheres na área de Computação, e vem sendo coordenada por docentes mulheres do Departamento de Ciência da Computação da Universidade de Brasaília (UnB). Dentre as atividades do projeto, uma tem se destacado nos últimos dois 
anos, que é a solução de desafios na área de computação, de maneira integrada entre alunas da UnB e do Ensino Médio, público. Este artigo tem como objetivo relatar essas experiências.

Este artigo está dividido nas seguintes seções. Na Seção 2, é descrita a metodologia dos desafios, resolvidos de forma integrada entre o Ensino Médio e a Universidade. Na Seção 3, são apresentadas as atividades realizadas em 2015. Na Seção 4, são ressaltados aspectos importantes das atividades do projeto. Por fim, na Seção 5, este artigo é concluído.

\section{Metodologia}

Esta seção apresenta a metodologia utilizada no projeto Meninas.comp, no que tange ao desenvolvimento de desafios, trabalhados entre alunas do Ensino Médio e da Universidade. A metodologia é composta pelas fases, descritas detalhadamente em seguida (Figura 1): definir a equipe, planejar os desafios, desenvolver os desafios e apresentar os resultados.

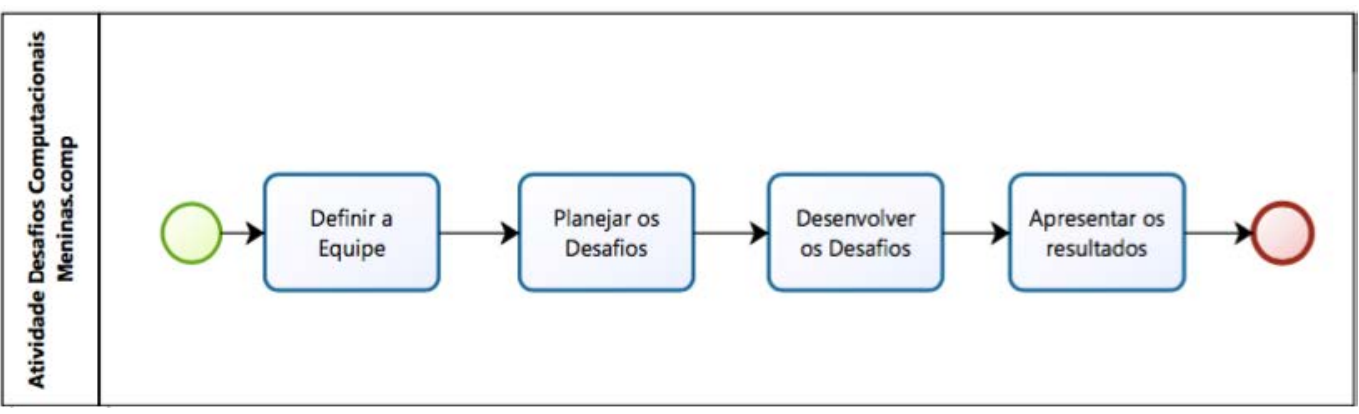

Figura 1. Metodologia da Atividade Desafios Computacionais.

\subsection{Definir a Equipe}

No início do ano, é definida a equipe composta por alunas de Ensino Médio e da graduação da UnB, que têm interesse em participar do projeto. Para escolher as alunas do Ensino Médio, é fundamental a participação do Professor da Escola de Ensino Médio na qual o projeto será executado. Esse Professor tem como missão divulgar o projeto e convidar as alunas.

Em seguida, após a definição da equipe da Escola, o projeto Meninas.comp é apresentado em uma reunião na própria Escola, que conta com a participação das docentes da Universidade de Brasília, do Professor da Escola e das alunas do Ensino Médio e da Universidade. Esse primeiro contato entre as alunas e os Professores visam integrar todas as pessoas envolvidas no projeto. Um resultado importante dessa reunião é a definição do horário e local das reuniões semanais, que também ocorrem na Escola.

\subsection{Planejar os Desafios}

Em seguida, são realizadas reuniões de discussões de possíveis problemas (desafios). Nessa etapa, é importante que as alunas do Ensino Médio tragam ideias a serem implementadas na vigência do projeto, por 1 ano. Assim, os desafios nascem das próprias alunas do Ensino Médio, devendo ser as suas soluções implantados em conjunto com as alunas de graduação. Nesse processo, os professores do Ensino Médio e da Universidade atuam como moderadores. Essa etapa pode necessitar de mais de uma reunião, pois além 
dos desafios, deve-se definir as necessidades de equipamentos e de conhecimentos, que permitam desenvolver as atividades que solucionarão os desafios.

Um aspecto importante é que o projeto tenha suporte financeiro que permita adquirir os equipamento. No caso do Meninas.comp, ao longo dos 6 anos de execução do projeto, alguns equipamentos utilizados durante as suas atividades foram comprados, dentre eles: Kit lego educacional, robôs sparks, placas de Arduino, diferentes sensores (temperatura, umidade, presença, dentre outros) e notebooks.

\subsection{Desenvolver os Desafios}

Como as atividades dos desafios são realizadas principalmente na Escola, o papel do Professor da Escola e o apoio do Diretor são fundamentais, pois é necessário um espaço físico onde as atividades possam ser desenvolvidas, todas as semanas.

Nas reuniões semanais, a primeira atividade é uma aula que discute os conceitos básicos necessários para as soluções dos desafios. Essas aulas podem ser ministradas pelos Professores ou por alunas da Universidade. Neste ano de 2016, o projeto tem atividades de programação e conhecimento básico de Arduíno.

Em seguida, a implementação dos desafios é desenvolvida. As alunas do Ensino Médio são divididas em grupos, onde cada grupo deve implementar um desafio diferente. Apesar dos desafios serem diferentes, estimula-se uma forte integração entre todas as meninas, de forma que cada aluna possa participar de mais de um desafio.

Durante as soluções dos desafios, acontecem visitas nos laboratórios da UnB, nas quais são discutidos temas relacionados a esses desafios. Esses encontros são importantes, pois as meninas do Ensino Médio podem ter contato direto com alunas e alunos da Universidade que trabalham com temas de pesquisa semelhantes.

\subsection{Apresentar os Resultados}

Nessa etapa, os projetos são apresentados em feiras de ciência, locais, regionais e nacionais (como na Semana Nacional de Ciência e Tecnologia, promovido anualmente pelo MCTI). As próprias alunas do ensino médio apresentam os desafios e as soluções, implementados durante o ano, para outras alunas e alunos do Ensino Médio.

\section{Resultados das Atividades do Ano de 2015}

\subsection{Definir a equipe}

Em 2015, a equipe foi composta por 1 Professor e 6 alunas do Centro de Ensino Médio Paulo Freire (CEM Paulo Freire) do Governo do Distrito Federal, sendo 2 alunas do primeiro ano, 2 alunas do segundo ano, e 2 alunas do terceiro ano, todas bolsistas em programas de Iniciação Científica da UnB. A equipe da UnB foi composta por 3 docentes e 1 aluna do curso de Engenharia de Computação.

\subsection{Planejar as Atividades}

Após 3 reuniões iniciais de planejamento, foram definidos cinco desafios: construir estação meterológica com medição de temperatura e umidade; construir carro de controle remoto; realizar corrida com robôs spark; montar cubo mágico com o kit educacional do 
Lego; e construir uma casa inteligente composta de sensores controlados por placas Arduíno.

As alunas forma dividas em equipes para desenvolver as atividades dos desafios, tal que cada desafio tinha uma líder responsável pelo acompanhamento das atividades. Os Professores supervisionaram continuamente a realização das atividades.

\subsection{Desenvolver os Desafios}

As atividades foram realizadas principalmente no CEM Paulo Freire, às sextas-feiras à tarde, quando aconteciam as reuniões do projeto. Algumas visitas na UnB foram realizadas. A visita mais relevante para as atividades de 2015 foi feita no Laboratório de Robótica DROID, onde as alunas do ensino médio conheceram alunas do ensino superior que também desenvolviam pesquisas com a placa Arduíno e com robôs spark.

\subsection{Apresentar os Resultados}

Os desafios desenvolvidos podem ser visto na Figura 2. Na Figura 2a, é mostrada a estação meterológica com placa Arduino e sensores de temperatura e umidade. Na Figura $2 b$, tem-se a casa inteligente com sensor de presença e sensor de iluminação, dentre outros controlados com Arduíno. Na Figura 2c, são apresentados os projetos com o robô lego: montagem do cubo mágico, robôs sparks que andam na mesa sem cair, e o carrinho com controle remoto desenvolvido pelas alunas.

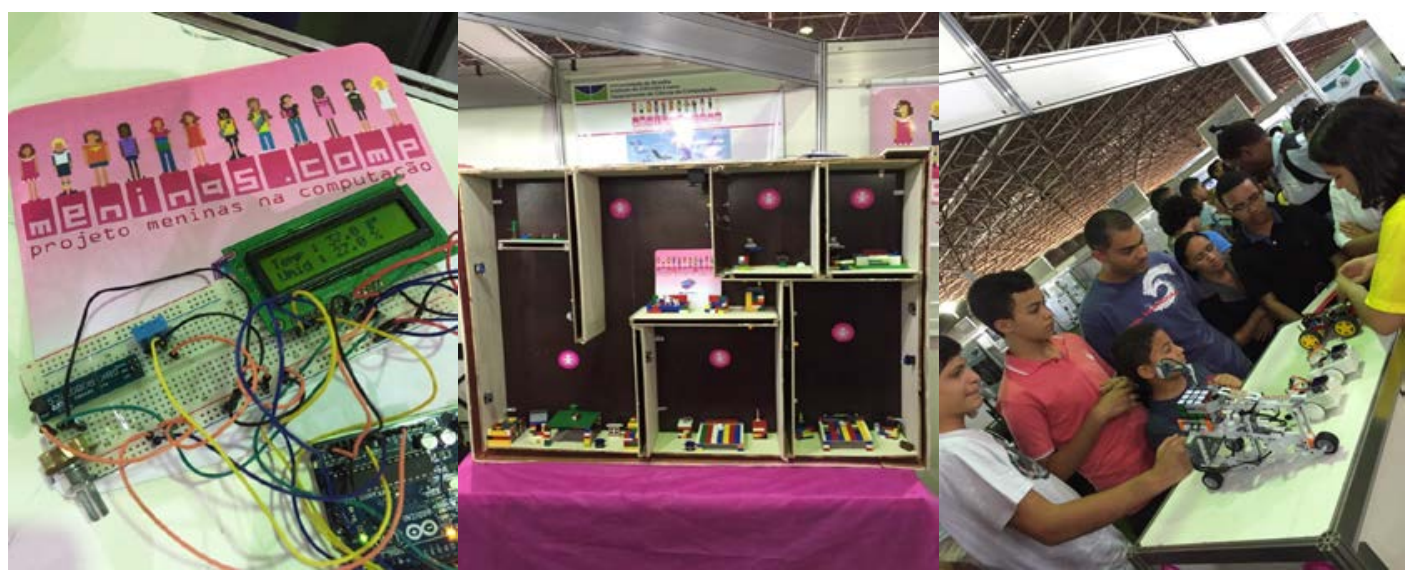

a) Estação Meteorológica.

b) Casa Inteligente.

c) Projeto com robôs

Figura 2. Projetos Implementados em 2015.

\section{Discussão}

Após seis anos de realização do projeto Meninas.comp, por docentes mulheres do Departamento de Ciência da Computação da UnB, com diferentes ações em Escolas de Ensino Médio público do Distrito Federal, os seguintes pontos devem ser destacados:

- Ter um professor responsável na escola de ensino médio é fundamental para o sucesso do projeto, pois ele conhece a rotina da escola, os locais disponíveis para reunião, os horários das aulas, e tem acesso direto às alunas e ao Diretor;

- Ter alunas da Universidade envolvidas no projeto, pois a linguagem usada é muito importante para a comunicação. Assim, uma jovem universitária fala "de igual para igual" com as alunas de ensino médio, facilitando a comunicação; 
- Trazer as alunas do ensino médio para visitas nos laboratórios da Universidade também foi uma excelente experiência, pois isso diminui a distância ente as Escolas públicas de Ensino Médio e a Universidade, além de motivar as alunas a acreditarem que é possível ingressar em uma Universidade Pública Federal.

\section{Conclusões}

A área de Computação, nos últimos anos, tem tido a participação de um número pequeno de profissionais mulheres, indicando que as meninas não têm tido interesse em se formar e seguir carreira na área. Neste contexto, o projeto "Meninas.comp" tem como objetivo divulgar a área de Computação para as meninas do ensino médio e público, e vem sendo realizado já há seis anos.

Esse artigo apresentou as ações e resultados do projeto na atividade de desafios computacionais, realizados em 2015. Notamos que duas das alunas integrantes do projeto, que cursavam o terceiro ano em 2015, agora são alunas da Universidade de Brasília, dos cursos de Física e Arquitetura.

Para finalizar, é fundamental o financiamento para o sucesso do projeto. As atividades previstas, decorrentes dos desafios, só puderam ser desenvolvidas em razão da compra dos equipamentos, propiciada por editais de 2013 e 2014 do CNPq, o que também permitiu consolidar a integração entre alunas e Professores do Ensino Médio e da Universidade.

\section{Agradecimentos}

Agradecemos a Universidade de Brasília que apoiou o projeto desde a sua criação em 2010, e ao CNPq, que apoiou o projeto em 2013 por meio do Edital Forma Engenharia, e em 2014 com o Edital Mulheres nas Exatas. Por fim, gostaríamos de agradecer especialmente ao Centro de Ensino Médio Paulo Freire do Governo do Distrito Federal que tem apoiado o projeto desde 2013.

\section{Referências}

Cohoon, J. McGrath. (2002) Recruiting and retaining women in undergraduate computing majors (2002). ACM SIGCSE Bulletin - Women and Computing. Vol. 34 (2), pp. 4852, ACM. USA.

Gurer, Denise and Camp, Tracy (2002). An ACM-W literature review on women in computing. ACM SIGCSE Bulletin - Women and Computing. Volume 34 Issue 2, June 2002 pp. 121-127.

Maia, Marcel Maggion. (2016). Limites de gênero e presença feminina nos cursos superiores brasileiros do campo da computação. Cadernos Pagu. n.46, pp. 223-244. ISSN 1809-4449. http://dx.doi.org/10.1590/18094449201600460223.

Khan, Nazish Zaman and Luxton, Andrew (2016). Is computing for social good the solution to closing the gender gap in computer science?. Australasian Computer Science Week Multiconference. DOI: 10.1145/2843043.2843069. 